\title{
THE RESPONSE OF ACUTE ANTERIOR POLIOMYELITIS TO THE ADRENERGIC BLOCKING AGENTS AND HOT PACK THERAPY
}

\author{
BY \\ WILLIAM W. WHITTEN and JAMES G. KRAMER \\ From the Department of Pediatrics, Children's Hospital, Akron, Ohio
}

(RECEIVED FOR PUBlication JUNE 3, 1953)

The therapeutic approach to poliomyelitis thus far must concern itself with the relief of so-called muscle spasm and the prevention of deformities. Since the advent of the modern concept of muscle spasm there has been a general trend toward the use of hot pack therapy, because it is thought that spasm is an inherent pathological mechanism within the muscle itself (Pohl, 1942, 1947) essentially divorced from the central nervous system, and therefore local therapy is the most rational approach.

The mechanism of muscle spasm has been attributed by various authors to meningeal irritation, irritation of the posterior horns and ganglia, shortening of the antagonistic muscles (Moldaver, 1943), vasoconstriction from sympathetic hyperaction (Smith, Rosenblatt and Limauro, 1949 ; Guyton, 1949) and involvement of the internuncial cells of the spinal cord (Kabat and Knapp, 1944). Bodian has produced muscle spasm in experimental animals. Examination of the central nervous system has shown involvement of the reticular formation of the hindbrain, the vestibular nuclei, precentral gyrus and the roof nuclei of the cerebellum (Bodian, $1946,1947,1949)$. In this regard it has been suggested by Faber that the primary site of viral invasion is the peripheral ganglia of the upper respiratory and alimentary tracts with involvement of the brain (Faber, 1950).

The identification and definition of muscle spasm has been the subject of much discussion. Pollock and his group of neurologists (Pollock, Boshes, Finkelman, Chor, Hiller, Brown, Arieff, Liebert, Tigay, Schiller and Sherman, 1949) found no evidence of spasm in a large series of cases observed clinically. Laboratory evaluation of muscle spasm by the use of action potentials has given conflicting conclusions. Harell, Mead and Mueller (1950) studied 100 cases and observed persistent electrical activity in only two cases while Schwartz and Bouman (1942) and Bouman and Schwartz (1944) found it was quite common with the same type of studies. The weakness of all this work appears to be the technique used, and until some more applicable method is found the presence of true spasm will be open to conjecture. Certainly in most cases of poliomyelitis muscle spasm can be demonstrated clinically. Smith and his associates have proposed that muscle pain and spasm in most cases is due to an imbalance in the autonomic nervous system whereby the sympathetic nervous system dominates the homeostatic mechanisms of the body (Smith, Graubard, Goldstein and Bikoff, 1948). Together with the pathological evidence cited above, the occurrence of urinary retention, constipation, vomiting, tachycardia, hypertension, cyanosis and decreased temperatures of the extremities, and excessive diaphoresis suggests a sympathetic predominance. With this reasoning they treated acute cases of poliomyelitis with 'priscoline', an adrenergic blocking agent, in an attempt to relieve muscle pain and spasm without the use of hot packs. As their investigation was an uncontrolled pilot study, we have sought to investigate in a controlled series the efficacy of 'priscoline'* (2-benzyl-4, 5 imidazoline) hydrochloride and 'dibenamine' $\uparrow(N, N$-dibenzyl-bchloroethylamine).

\section{Method}

The patients selected for study were those in the acute stage who showed a suggestive history of poliomyelitis, definite pleocytosis in the spinal fluid, and signs of severe muscle spasm with or without paralysis. Ten per cent. had respiratory or bulbar involvement or both, the remainder being of the spinal type. Subjective resting pain was evaluated by careful questioning of the adult patients. Changes in the tightness of the muscles were measured by serial goniometric determinations, including flexion

\footnotetext{
* Ciba Pharmaceutical Products, Inc., Summit, New Jersey, U.S.A. U.S.A.
} 
of the neck and back, straight leg raising and extension of the leg on the thigh. These were performed by the same observer and noted on special charts together with the occurrence of urinary retention and constipation. Laboratory examination included examination of the urine and complete blood counts at least once a week.

Some evaluation of the blood flow in the muscles was deemed of importance in order to investigate the status of the vascular system before and after treatment, and for this purpose a Leeds and Northrop recording potentiometer was used. Iron constantan thermocouples in No. 192 in. needles were inserted in the muscle at a $45^{\circ}$ angle. The skin thermocouples were secured to the skin with adhesive tape. Although it was not possible to have a room maintained at a constant temperature, frequent observations on the room temperature were made and a cradle was placed over the patient's extremities. The patients were not in a strictly basal state but recordings were made after a control period of half an hour before therapy was instituted. Pulse and blood pressure readings were taken every 15 minutes for the first two hours, then every four hours for two days. Oscillometric indices were also done in a limited number of cases in an attempt to evaluate the state of the large vessels.

Because of the nature of the cases used for the study it was impossible to assign each case in rotation to a particular group. Also, with the exception of a few cases a control group was not studied.

'Dibenamine' to be effective must be given intravenously since extravasation into the tissues causes necrosis, therefore only older children (over 12) and adults were included in this group. The group treated with 'priscoline', on the other hand, encompassed children ranging from 1 year of age and adults. The group treated with hot packs had a wide age range.

Consultation with the physical therapy department was held on most of the cases so that a full evaluation of the different groups might be accomplished.

\section{Dosage}

Priscoline. Arbitrarily the children under 10 years of age were given $25 \mathrm{mg}$. of 'priscoline' intramuscularly for the first dose, and this was increased by $12.5 \mathrm{mg}$. increments every four hours until a cutaneous flush appeared. Children over 10 years of age were started at $50 \mathrm{mg}$. with the same increase in dosage for two to three days, when the oral route was exchanged for the intramuscular route at the same dosage. The biggest dose given in this series was $150 \mathrm{mg}$. every four hours. It was noted that most cases had to have persistent increases in 'priscoline' to maintain the so-called 'flushing' effect which was presumed to be the maximum possible therapeutic result.

Dibenamine. All patients received $6 \mathrm{mg}$. 'dibenamine' per kg. of body weight intravenously. Since this agent is a cerebral cortical stimulant, $1 \frac{\bar{z}}{8}$ to $3 \frac{3}{4}$ grains of sodium amytal was given intravenously before 'dibenamine' was given. Utilizing a doublebottle intravenous set, in which one bottle contained the 'dibenamine' mixture with saline and the other plain saline, a needle was introduced into the vein after the plain saline had been run through the tubing to eliminate any unnecessary extravasation of 'dibenamine'. With the intravenous saline flowing, sodium amytal was injected into the tubing but was not given into the 'dibenamine' solution as it tends to precipitate. The 'dibenamine' was run at 80 drops per minute, and following its administration $50 \mathrm{ml}$. of saline was run through to flush out the vein and thereby eliminate most of the danger of thrombophlebitis. Blood pressure and pulse readings were taken every half hour for four hours, every four hours for two days, and once a day thereafter.

\section{Clinical Results}

A significant statistical comparison of the results of all forms of therapy-hospital stay, ultimate disability, etc.-was impossible because of the small series of cases treated; however, certain impressions were received from this limited group and, since other studies of this nature have not been reported, the results should be interesting.

Hot Packs. Although 82 cases were treated with hot packs only 25 cases were sufficiently severe to be worth evaluating. In most cases pin packs were used from six to 12 hours a day, being left on one to two hours. In regard to pain, the rapidity of relief following hot packs compared with drug therapy was not overly impressive. It should be noted, however, that severe pain was present in only six of the 25 cases in this group. The relief of muscle spasm has been observed to be less rapid than in those cases which were successfully treated with drugs; however, a larger percentage showed definite improvement over a long period.

Priscoline. A group of 33 cases was treated with 'priscoline' and the overall age distribution was approximately the same as those treated with hot packs. In regard to relief of pain, all but three of the 24 cases who had moderate to severe pain were relieved within four to eight hours after the institution of therapy. It was our impression that in certain 
cases where large amounts of various analgesic agents were used, the use of 'priscoline' was far superior for the relief of this type of subjective pain. The results of the treatment for muscle spasm were quite variable. Some cases responded dramatically at first, only to have a remission of symptoms within four or five days, while others progressed towards complete improvement. Another group did not show any appreciable change despite persistent therapy. A fourth group which did not react to 'priscoline' showed a favourable response to 'dibenamine'. In general it can be said that about half of all the cases treated with 'priscoline' showed an improvement which was sufficiently definite not to be attributable to the natural course of the disease and was sufficiently favourable to warrant the use of this drug.

Dibenamine. Dibenamine has not been previously used in the treatment of acute poliomyelitis and therefore our impression of the 27 cases treated awaits further evaluation. The relief of muscle pain within one hour of the initial intravenous dose paralleled that of 'priscoline' in that 13 of the 16 cases with pain were relieved. In some cases the pain would return in $\mathbf{4 8}$ to $\mathbf{9 6}$ hours after therapy, indicating the length of action of the drug and the fact that disappearance of pain was not spontaneous. Muscle spasm, as with those cases treated with 'priscoline', reacted in various ways and from a statistical point of view did not show any great difference. It was thought, however, that 'dibenamine' was, in a certain number of cases, superior to 'priscoline'. The favourable results from a numerical point of view would have been greater in the 'dibenamine' group had repeated intravenous rather than oral doses been given since the oral method is almost completely ineffective. It was not until most of the cases had been treated, however, that repeated intravenous injections were given at two-to-three day intervals. Therefore an evaluation of prolonged therapy cannot be made now. Because of the tentative nature of these two drugs from a therapeutic point of view, approximately one-half of the cases were eventually given hot pack therapy. In many cases, although the actual extent of mobility was not increased as determined by the goniometer, the presence of stretch pain was either eliminated or diminished in intensity. The relief of this type of pain appeared to us to be of greater degree than that observed when hot packs had been used. In these cases early physical therapy could be instituted.

Toxicity. 'Priscoline', although relatively nontoxic, did produce anorexia, nausea or vomiting in about $20 \%$ of the cases. This was of little consequence early in the treatment as the intramuscular route was utilized. However, when, because of local pain, the oral route was chosen gastric irritation did occur. There were also other reactions, such as chilling and headache, but in few cases. It was often noticed that flushing of the skin would disappear following two or three days' therapy, and from this reaction and the return of muscle pain and spasm it was felt that tolerance might have developed to this drug. Four bulbar cases and one encephalitic case showed no unusual or untoward reactions.

The toxicity of 'dibenamine' was shown in local reactions, in the gastro-intestinal system and in the central nervous system. Local pain during injection was not uncommon but thrombophlebitis occurred in only three cases. Nausea and vomiting were uncommon, the latter occurring in only two cases, following intravenous medication. No convulsive seizures occurred but gross tremors did occur in four patients, one of whom needed 15 grains of sodium amytal intravenously before the shaking ceased. The nasal mucosa became swollen in five cases. Reduplicative para-amnesia occurred in one case but lasted only four hours. Tachycardia and orthostatic hypotension were not observed. Myopic, fixed pupils were noticed in a majority of cases for about one day. Three bulbar and three respiratory cases given the drug showed no toxic reactions.

Oral 'dibenamine' was given the third day after the intravenous dose in amounts varying from 260 to $980 \mathrm{mg}$. divided in thirds and given after meals. The dosage was calculated empirically as $50 \%$ greater than the intravenous medication. Oral atropine was given before meals in order to decrease the nausea and vomiting, which nevertheless occurred in two cases.

\section{Laboratory Studies}

To date little work has been done on the physiology of muscle pain and spasm. Since it has been postulated that muscles in spasm may be the result of tissue ischaemia on a vaso-spastic basis, we explored this possibility by measuring the blood flow in muscle so that the rationale of increasing the circulation might be maintained. For this purpose the muscle and skin temperatures were studied together with oscillometric indices. We did not examine a large number of patients with the oscillometer for in all of them there was no diminution of the diameter of blood vessels as measured by this method, as opposed to the observations of Smith et al. (1948). Indeed, it was noted that following 'priscoline' therapy the oscillometric index in certain cases decreased. We were unable to explain this paradoxical result and felt that this method of evaluation was too gross to establish any facts. 
Muscle temperature studies were done on a continuously recording Leeds and Northrop 'speedomax' potentiometer. The three groups of muscles investigated were 'spastic', partially or completely paralysed, and normal. Determinations were run from three to eight hours, and the effect of three methods of therapy on three groups of muscles was investigated. It was interesting to note that the so-called spastic muscles had a greater muscle temperature $\left(99 \cdot 3^{-}\right.$F.) than the normal $\left(98 \cdot 2^{-}\right.$F.) and that the temperature of paralysed muscles $\left(99 \cdot 2^{-}\right.$F.) fell between these two. Secondly, the response to all forms of therapy was greater, in terms of increase in muscle temperature, in weak muscles. The mean duration of increased muscle temperature was 115 minutes for hot pack therapy, 135 minutes for 'priscoline', and 218 minutes for 'dibenamine'. 'Dibenamine' maintained the elevation for at least eight hours during the longest tests, and clinically the symptoms indicated a duration of 48 to 96 hours. The greatest increase in muscle temperatures was noted following treatment with 'priscoline' $\left(2 \cdot 0^{\circ}\right.$ F.) although the difference between the mean increase is of little practical importance. In studying individual muscles the greatest increase in temperature was noted following hot pack therapy $\left(5 \cdot 4^{\circ} \mathrm{F}\right.$.). Skin temperature studies were of interest only in a relative sense because the patients were not in a true basal state, and secondly, because a constant temperature room was not available. The mean increase was greater following 'dibenamine' $\left(2 \cdot 5^{*}\right.$ F.) than 'priscoline' $\left(1 \cdot 9^{\prime}\right.$ F. $)$.

\section{Discussion}

It is obvious that determinations of temperature in muscle do not differentiate between blood flow in the tissues and metabolism. Therefore it cannot be said unequivocally that spastic and paralysed muscles do not have a decreased blood supply. However, it does seem evident that the amount of ischaemia cannot be of any great significance from a vaso-spastic point of view. It is, of course, paradoxical that a higher temperature was found in spastic muscles, and it is suggested that this may be a result of the increased tissue metabolism from the contractions of the muscle fibres in spasm. If this is true, even if the main arterial supply is unaltered, the tissue needs may be of such intensity as to cause relative ischaemia in muscle. By increasing the blood supply with packs or vasodilators, we may be relieving this relative ischaemia and either supplying the necessary oxygen for re-oxidation of lactic acid to glycogen or removing the oxidation waste products, thereby eliminating their presence which may contribute to the pain of this disease.
The second paradoxical result of this work was the greater increase in temperature of the weak muscles following therapy than in either spastic or normal muscles. Also, it is to be wondered why paralysed muscles have a higher temperature before therapy than normal muscles. It is thought that the fibrillation in completely or partially denervated muscles increases tissue metabolism (Best and Taylor, 1950) and therefore temperature, and that this was occurring to a sufficient extent to create a higher temperature than was observed in normal muscle. The increase in temperature following dosage of 'priscoline' and 'dibenamine' might be rationalized by the fact that fibrillation of muscle fibre is thought to result from a hypersensitivity to acetylcholine. Since these adrenergic blocking agents enhance the action of acetylcholine the fibrillation may be increased following these drugs. and therefore an increased temperature results. The fact that the weak muscles responded similarly following hot pack therapy is statistically insignificant and needs further investigation.

Although results of this initial work shed some light on the conflicting views which have been proposed, it is evident that further physiological studies are indicated before the final thoughts on these matters will be known.

\section{Summary}

Relief of severe subjective pain at rest is practically always accomplished within one-half to eight hours with 'priscoline' or 'dibenamine' whereas packs are much less effective and take considerably longer.

Relaxation of muscle spasm with drug therapy was either quite definite or completely absent. suggesting that more than vaso-spasm may be involved aetiologically. At least $50 \%$ of the cases responded favourably enough to eliminate the need for hot packs.

Although actual limitation of mobility might still remain after drugs in some cases, stretch pain in muscle was frequently eliminated, permitting early physical therapy.

Initial improvement with drugs in some cases was superseded by more severe spasm in five to six days. In those cases tested with 'dibenamine' this was found to result from the use of the oral route which is ineffective.

Early active and passive motion within the limits of pain must be instituted with drug therapy if favourable results are to be obtained.

Genito-urinary and gastro-intestinal dysfunctions were unaltered by any form of therapy.

No severe toxicity was observed with either drug: however, the use of 'dibenamine' is not without 


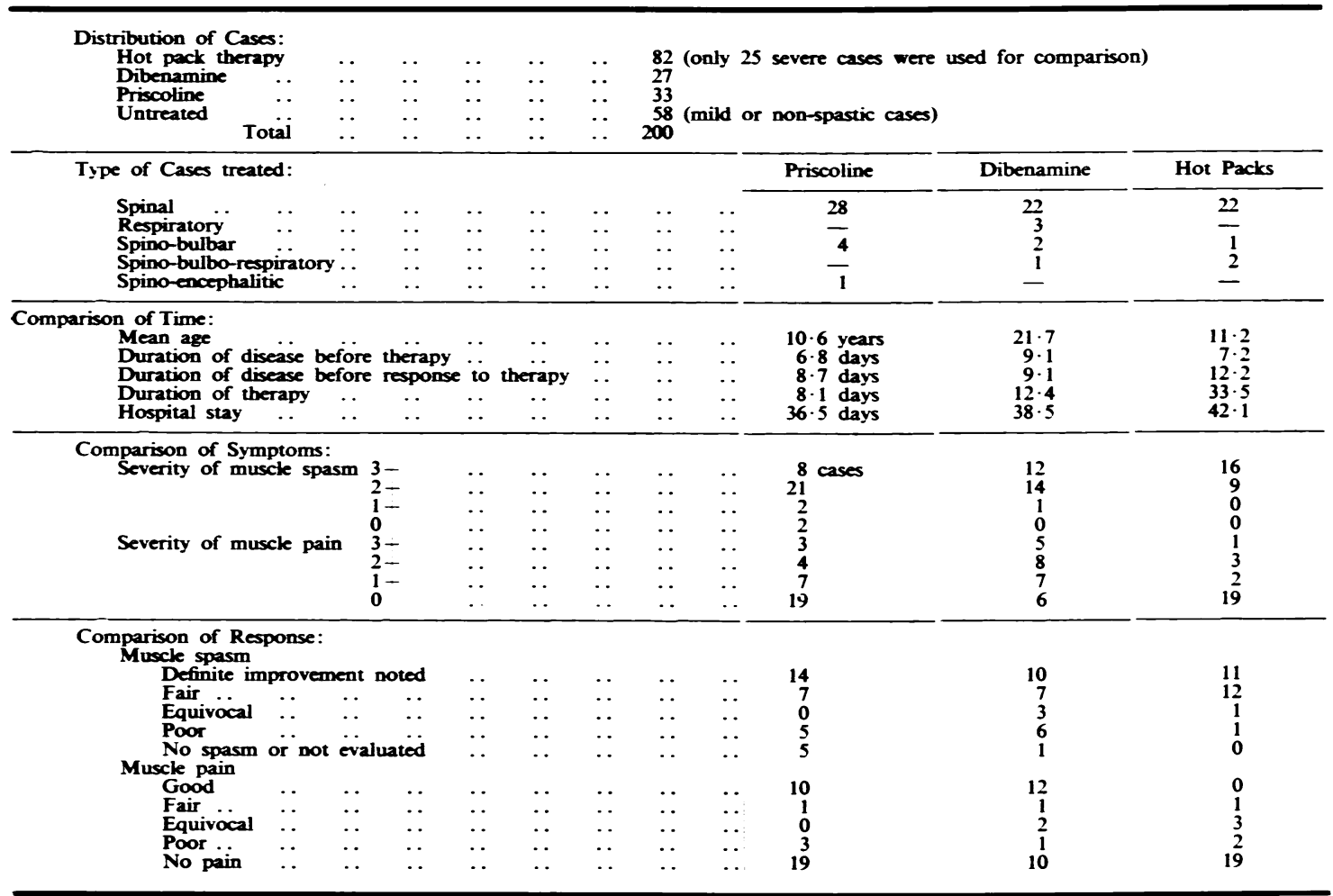

danger. It must be used with caution, with careful observation of the patient during administration.

In general, drug therapy is worthy of trial in most cases of poliomyelitis as the presence or lack of response will be quickly evident. Thus early use of hot packs, if necessary, will not be delayed.

In this study, the muscles in poliomyelitis with the greatest temperature were those in spasm, followed by weak and then by normal muscles.

Response to therapy in terms of temperature of muscle was greatest in the case of weak muscles.

No abnormally low skin temperatures were observed and the response to 'dibenamine' was more marked than to 'priscoline'.

In terms of muscle temperature the effective therapeutic response was greatest in the case of 'dibenamine' followed by 'priscoline' and by hot packs.

No obvious absolute ischaemia in muscle was noted, but it is suggested that increased tissue metabolism may create a relative anoxia which may be relieved by an increase in blood flow. Hypersensitivity of denervated muscles to acetylcholine may be enhanced by adrenolytic agents and therefore explain the marked temperature increase following therapy.

Further studies on tissue metabolism and blood flow are indicated before an adequate explanation will be available for muscle spasm and pain.

\section{REFERENCES}

Best, C. H. and Taylor, N. B. (1950). The Physiological Basis of Medical Practice, 5th edit., p. 1461. Baltimore.

Bodian, D. (1946). Proc. Soc. exp. Biol., N.Y., 61, 170. (1947). J. Amer. med. Ass., 134, 1148.

(1949). Amer. J. Med., 6.563.

Bouman, H. D. and Schwartz, R. P. (1944). N.Y. St. med. J., 44, 147. Faber, H. K. (1950). Pediatrics, 6. 488.

Guyton, A. C. (1949). Arch. intern. Med., 83, 27.

Harell, A., Mead, S. and Mueller, E. (1950). J. Amer. med. Ass., 143, 640 .

Kabat, H. and Knapp, M. E. (1944). J. Pediat., 24, 123.

Moldaver, J. (1943). J. Amer. med. Ass., 123, 74.

Pohl, J. F. (1942). Ibid., 118, 1428.

Poh, (1947). J. Bone Jt Surg., 29, 1027.

Pollock, L. J., Boshes, B., Finkelman, I., Chor, H., Hiller, F., Brown M., Arieff, A. J., Liebert, E., Tigay, E. L., Schiller, M. and Sherman, I. C. (1949). Arch. Neurol. Psychiat., Chicago, 61, 288.

Schwart, R. P. and Bournan, H. D. (1942). J. Amer. med. Ass., $119,923$.

Smith, E., Graubard, D. J., Goldstein, N. and Bikoff, W. (1948). N.Y. St. med. J., 48, 2608 .

_- Rosenblatt, P. and Limauro, A. B. (1949). J. Pediat., 34, 1. 